September 2021

\title{
Encouragement Is Not Enough: Perceptions and Attitudes towards Corrective Feedback and Their Relationship to Self- Efficacy
}

\author{
Vasti Holstun \\ Liberty University \\ Neil Rigsbee \\ Adams State University \\ Lynn Bohecker \\ Liberty University
}

Follow this and additional works at: https://trace.tennessee.edu/tsc

Part of the Counselor Education Commons

\section{Recommended Citation \\ Holstun, Vasti; Rigsbee, Neil; and Bohecker, Lynn (2021) "Encouragement Is Not Enough: Perceptions and Attitudes towards Corrective Feedback and Their Relationship to Self-Efficacy," Teaching and Supervision in Counseling: Vol. 3 : Iss. 3 , Article 2. \\ https://doi.org/10.7290/tsc030302 \\ Available at: https://trace.tennessee.edu/tsc/vol3/iss3/2 \\ This article is brought to you freely and openly by Volunteer, Open-access, Library-hosted Journals (VOL Journals), published in partnership with The University of Tennessee (UT) University Libraries. This article has been accepted for inclusion in Teaching and Supervision in Counseling by an authorized editor. For more information, please visit https://trace.tennessee.edu/tsc.}




\title{
Encouragement Is Not Enough: Perceptions and Attitudes Toward Corrective Feedback and Their Relationship to Self-Efficacy
}

\author{
Vasti P. Holstun, Neil P. Rigsbee, Lynn Bohecker
}

This correlational study explored the relationship between feedback and counselor self-efficacy during online counselor education residency. Participants $(N=145)$ were students from eight online counseling programs accredited by the Council for Accreditation of Counseling and Related Educational Programs (CACREP) who completed instruments on perceptions of positive and corrective feedback, attitudes toward corrective feedback, and counselor self-efficacy. Results showed a significant positive correlation between perceptions of corrective feedback and self-efficacy. Two factors related to perceptions of corrective feedback also showed significant correlations with self-efficacy. Implications concerning providing corrective feedback in supervision for counselor in training are discussed.

Keywords: self-efficacy, corrective feedback, online counselor education, counselor supervision, correlational research

The concept of feedback has an extensive interdisciplinary history, originating in engineering and cybernetics (Claiborn \& Goodyear, 2005) and later adopted by social sciences as a measure of effective communication and social interaction (Bernard \& Goodyear, 2019). Within counselor education, feedback is part of supervision and is considered essential for learning and performance of counselors in training (CITs; Bernard \& Goodyear, 2019). Supervisors share their perspective of CIT skills through verbal and written communication. The intended outcome of hearing the thoughts of a supervisor is for CITs to integrate the feedback and make changes to their counseling skills (Bernard \& Goodyear, 2019). Feedback influences processes connected with CIT learning and one of these processes is self-efficacy (Daniels \& Larson, 2001).

Self-efficacy is a central component in Bandura's Social Cognitive Theory (SCT), which is well-connected with learning and impacts many aspects of human behavior (Bandura, 1977). Essentially, selfefficacy is the belief in one's ability to accomplish a task (Bandura, 1977). SCT conceptualizes behavior as involving triadic interactions among personal, behavioral, and environmental factors. The interaction among the three factors is contextual and behavior specific, and it depends upon the unique characteristics of the individual (Bandura, 1977). When SCT is applied to counselor education, CIT self-efficacy influences the pursuit of new learning, retention of new information, and performance in newly learned skills (Bandura, 1997). Therefore, since feedback influences self-efficacy, and self-efficacy influences learning, it is conceivable that there is a relationship between feedback and counseling self-efficacy in CITs. Of particular interest for this study was feedback found in the intensive residencies in online counselor education programs.

Feedback can be difficult as it includes evaluative connotations with negative and positive dimensions (Bernard \& Goodyear, 2019; Fickling et al., 2017). Negative feedback is a term that is interchangeable with critical feedback, constructive feedback, or corrective feedback (Bernard \& Goodyear, 2019). The authors of this study adopted the terms corrective feedback and positive feedback as having contrasting meanings. Corrective feedback is "intended to encourage thoughtful examination 
Perceptions Toward Corrective Feedback

and/or to express the feedback giver's perception of the need for change on the part of the receiver" (Morran et al., 1991, p. 410). Such feedback refers to the element of formative feedback in which the supervisor points out areas of growth. This is in contrast to positive feedback, where the supervisor identifies areas of mastery. Sanford (1967) posited that one of the most important tasks for educators in general is navigating the delicate balance of providing support and challenge. Both types of feedback appear to be essential components for CITs, however, few studies exist on the connection between feedback and CIT self-efficacy (Borders et al., 2014; Larson \& Daniels, 1998; Rønnestadt, \& Skovholt, 2003).

\section{Counselor Self-Efficacy}

Larson and Daniels (1998) believed counseling self-efficacy may be best understood in the context of SCT and highlighted the importance of feedback in supervision. Larson and Daniels (1998) defined counseling self-efficacy as “one's beliefs or judgments about her or his capabilities to effectively counsel a client in the near future" (p. 180). Daniels (1997) found that prior self-efficacy strength, state anxiety, and positive feedback accounted for $80 \%$ of the variance in counselor self-efficacy, and Watson (1992) found that factors such as coursework and counseling experience accounted for $35 \%$ of the variance in counselor self-efficacy. More recent research indicated that CITs' self-efficacy increased progressively between clinical experience courses, specifically when comparing the start of practicum with the end of internship (Mullen et al., 2015). Efstation et al. (1990) found that perceptions of supervisory style accounted for $14 \%$ of the variance in counselor self-efficacy and Hanson (2006) reported that supervisory alliance accounted for $31 \%$ of the variance in counselor self-efficacy. While counselor self-efficacy literature aligns with the focus of SCT, it also highlights the need to explore further the significance of supervision for professional counselor learning. A key component of supervision is providing feedback to CITs to hone the development of skills.

\section{Feedback in Counselor Education and Supervision}

From their first semester, CITs are exposed to personal and professional feedback, initially relying heavily on positive feedback (Bernard \& Goodyear, 2019; Swank \& McCarthy, 2013). CITs become more familiar with feedback as they developmentally progress through their program and begin to value supervision feedback when engaged in clinical courses (Bernard \& Goodyear, 2019; Rønnestadt, \& Skovholt, 2003). Feedback within supervision is an essential aspect of counselor training and is part of the broad SCT environment within which CITs develop counseling self-efficacy (Bandura, 1977; Borders et al., 2014; Meyer, 2012).

Feedback in supervision has been presented as atheoretical, meaning that supervisors provide feedback as a function of instruction regardless of theoretical orientation (ACES, 2011; Bernard \& Goodyear, 2019; Borders, et al., 2014). However, Bandura's (1977) SCT interactions of personal, behavioral, and environmental components apply to supervisory feedback. CITs can receive feedback from a supervisor or peers with a supervisory group (environmental component), interpret the feedback as positive or corrective (personal component), and decide to incorporate or show defensiveness against the feedback (behavioral component). Thus, connecting feedback with theory through SCT brings supervisory practices in harmony with learning and instructional best practices (Bandura, 1977; Stroud et al., 2016).

While students may consider themselves open to feedback, often barriers and social conventions connected to corrective feedback can get in the way of fully benefiting from the exchange (Christensen \& Kline, 2000; Ramani et al., 2017). Giving corrective feedback is often perceived as being socially inappropriate, making the delivery and reception of corrective feedback difficult (Swank \& McCarthy, 2013). CIT's perceptions toward corrective feedback and the supervisory relationship may have an impact on how they perceive and incorporate such messages (Hulse-Killacky et al., 2006; McKibben et al., 2019). Providing resources to navigate emotional discomfort may increase the ability to incorporate feedback (Bohecker et al., 2016; Rønnestadt, \& Skovholt, 2003). Compounding the difficulties 
with the discomfort and types of feedback are differences in cultural norms and values, which can add another dimension.

\section{Feedback and Culturally Sensitive Supervision}

In addition to an awareness of cultural social norms surrounding feedback, practicing supervision without a solid understanding of cultural diversity can be as harmful as malevolence (Quek \& Storm, 2012; Ramani et al., 2017). Supervisors who do not fully understand cultural values of CITs limit their ability to provide useful feedback and enhance CIT's self-efficacy (Quek \& Storm, 2012). Providing formative feedback appears to present cognitive challenges and psychological and emotional struggles for minority or international students who have not had enough time to acculturate (Tian \& Lowe, 2013). Hook and colleagues (2016) suggest that an important aspect of supervision is modeling and teaching cultural humility in CITs. Crockett and Hays (2015) found that supervisors' multicultural competence was related to the supervisory alliance, impacting CIT's satisfaction with supervision. This study also found a moderate correlation between supervisor's multicultural competence and CIT's selfefficacy in counseling.

A supervisor's ethnicity and culture as well as attitudes have an impact on the type of feedback they tend to give in supervision and how it is perceived by CITs, adding complexity to feedback (Bernard \& Goodyear, 2019; McKibben et al., 2019; Ramani et al., 2017). Suhoyo et al. (2014) replicated a Dutch study on training feedback in Indonesia and found that, while perceptions of the instructional value of feedback did not differ between the two countries, other differences were recorded. Indonesian participants found more value in feedback offered by specialists, while Dutch participants valued feedback generated by direct observation. Burkard et al. (2014) found that corrective feedback delivered by supervisors to their culturally diverse students about culturally insensitive instances in counseling had a profound impact on the supervisory relationship and other supervisory processes. Ramani et al. (2017) discovered that while positive feedback may be appreciated, it was also viewed as inauthentic. While cultural context awareness is crucial in providing feedback, corrective feedback may be perceived as more genuine and contributes to a positive productive supervisory experience.

Feedback perception varies not only with ethnicity, but also with generational values. Anderson et al. (2016) found that Millennials (born between 1982-2000) have different attitudes regarding negative feedback than previous generations and have difficulty accepting corrective feedback. Anderson et al. (2016) recommended supervisors provide consistent and ongoing corrective feedback to facilitate behavioral changes. Implications suggest that supervisors find ways to give ongoing corrective feedback to Millennial CITs so that it can be integrated. Thus, perceptions of feedback in supervision are influenced not only by culture, but also by generational values. Instructional modalities can add yet another dimension. For example, providing feedback during clinical residency in online programs may be particularly challenging.

\section{Online Learning in Counselor Education}

Before the pandemic, developments in technology created a growth in accredited online counselor education programs (Council for the Accreditation of Counseling and Related Educational Programs [CACREP], 2016; Papanagnou et al., 2015). In 2012 there were six CACREP-accredited online programs in the United States, and in 2019 the number had increased to 48 universities that were accredited or in the process of being accredited (CACREP, 2016; Meder, 2014). Many online programs include a face-to-face intensive clinical residency (CACREP, 2017). In early 2020, following the government stay-at-home orders due to the COVID-19 pandemic, counseling programs were forced to integrate some form of online learning, increasing the importance of studies focusing on providing feedback in online learning.

Residency trainings focus on clinical supervision and practice of counseling skills, however, in the literature there is a dearth of clear established norms in conducting residency trainings. A range of residency requirements exist where CITs may spend from 7-12 hours a day and between 5-10 consecutive days on campus. Most online programs required two separate residencies, although some programs required one and others required more than two (CACREP, 2017). 
During residency, CITs receive direct feedback, individually and in a group setting, by faculty and peers. For example, in a residency program experienced by the first and second authors, students are split up into small groups of six and take turns completing "fish bowl" exercises — where a "counselor" and a "client" engage in a counseling session. The rest of the group and the instructor observe and provide feedback, both corrective and positive. The "clients" are encouraged to bring up real issues for them, and made-up scenarios are discouraged. In a residency experienced by the third author, students are grouped into triads and are asked to rotate the roles of counseling, client, and observer with most of the feedback provided in verbal format from peers. Some programs encourage students to talk about actual situations during residency and other programs provide mock counseling scenarios that students need to role-play during sessions. Some programs focus feedback only on clinical skillbuilding during residency, and other programs additionally focus feedback on counselor identity and countertransference.

\section{Rationale of the Study}

While some studies address feedback in supervision, there is a paucity of studies that focus on feedback during clinical residency. Perceptions of feedback have been studied in face-to-face programs, but only with intentionally "bogus" (contrived) feedback (Daniels \& Larson, 2001, p.120). Extant literature highlighted that CIT perceptions of feedback are more important than the actual feedback in influencing CITs' decision to change (Sohn, 2009; Stroud et al., 2016). The impact of the supervisor's role on students' openness to feedback is an aspect recommended for further exploration (Stroud et al., 2016). Additionally, corrective feedback has negative connotations impacted by a CIT's prior experiences and cultural norms, which may be impacted by an intensive residency (Hulse-Killacky et al., 2006). Authentic feedback given in residency instructional settings has not been studied.

The purpose of this study was to investigate the relationship between perceptions of feedback and CIT self-efficacy when in an online program residency setting. Specifically, the authors were interested in how perceived positive and corrective feedback might correlate with self-efficacy, and how
CIT's attitudes toward corrective feedback might correlate with self-efficacy. For the purposes of this study, researchers distinguished between general attitudes toward corrective feedback and perceptions of specific feedback as two separate constructs. This study was based, in part, on previous studies about how CIT self-efficacy increased over time (Mullen et al., 2015), what influenced attitudes toward corrective feedback (Stroud et al., 2016), and factors impacting perceptions of feedback (Sohn, 2009). Two research questions guided this study: (1) What is the relationship between perceptions of feedback (corrective and positive) in a residency training setting, and self-efficacy? and (2) Is there a correlation between attitudes toward corrective feedback and self-efficacy?

\section{Method}

\section{Participants}

After obtaining institutional review board approval, the first author directly contacted 20 CACREP-accredited counseling programs that required a residency and posted recruitment messages on national counseling and school counseling forums and listservs. Of the 20 programs contacted, eight program coordinators, in turn, emailed master's students who were enrolled in residency training. Two of the programs were housed at public universities, and six programs were from private universities, out of which three identified as Christian.

The inclusion criteria were students currently enrolled in a CACREP-accredited online program that included a residency component. The recruitment message included a link to the informed consent. Upon agreement, participants were directed to complete a demographic questionnaire, the Perceptions of Feedback Instrument, the Corrective Feedback Instrument-Revised, and the Counselor Self-Efficacy Scale in Survey Monkey. Exclusion criteria for participation in this study were counseling programs that did not require a residency or had not yet conducted a residency training. Graduate students who had not attended a residency training or who identified as being students in a face-to-face program were excluded from the study.

Based on the a priori power analysis, a minimum of 115 participants were needed to detect a medium 
size effect. A total of 171 participants attempted the survey with a completion rate of $84 \%$, which was deemed adequate (Sterner, 2011). All data were examined for missing scores. Incomplete (unfinished) questionnaires were eliminated from the final data set. Random missing data was addressed through mean imputation (Sterner, 2011). Nonrandom missing data was eliminated through listwise deletion (Green \& Salkind, 2014). The final number of participants was 145 master's-level CIT's enrolled in eight different online CACREP-accredited counselor education programs. Participant demographic information is provided in Table 1. For residency completion, 75 participants indicated they completed one residency (52.4\%), 64 participants indicated that they completed two residencies (44.4\%), and 5 participants indicated that they completed three residencies $(2.8 \%)$. One participant did not indicate how many residencies had been completed and was subsequently eliminated through listwise deletion.

\section{Instrumentation}

The instruments used in this study were the Counselor Self-Efficacy Scale (CSES; Melchert et al., 1996), the Corrective Feedback Instrument-Revised (CFI-R; Hulse-Killacky et al., 2006), the Perceptions of Feedback Instrument (PFI), and a demographic questionnaire.

Counselor Self-Efficacy Scale (CSES). The authors used the CSES (Melchert et al., 1996) as it was designed specifically to measure the counseling self-efficacy of CITs. The CSES is a 20-item, 5point Likert scale self-report instrument assessing key counseling task competencies for both group and individual counseling in counseling trainees (Melchert et al., 1996). To prevent acquiescent response bias, half of the items are worded negatively, requiring reverse coding. Total scores can range from 20-100.

The initial testing of the CSES was completed with counseling psychology students and licensed professional psychologists. The researchers tested for evidence of convergent validity and found an acceptable correlation ( $r=.83 ; p$-value not reported) between the CSES and the Self-Efficacy Inventory (Friedlander \& Snyder, 1983). In their initial psychometric testing of the CSES, the developers of

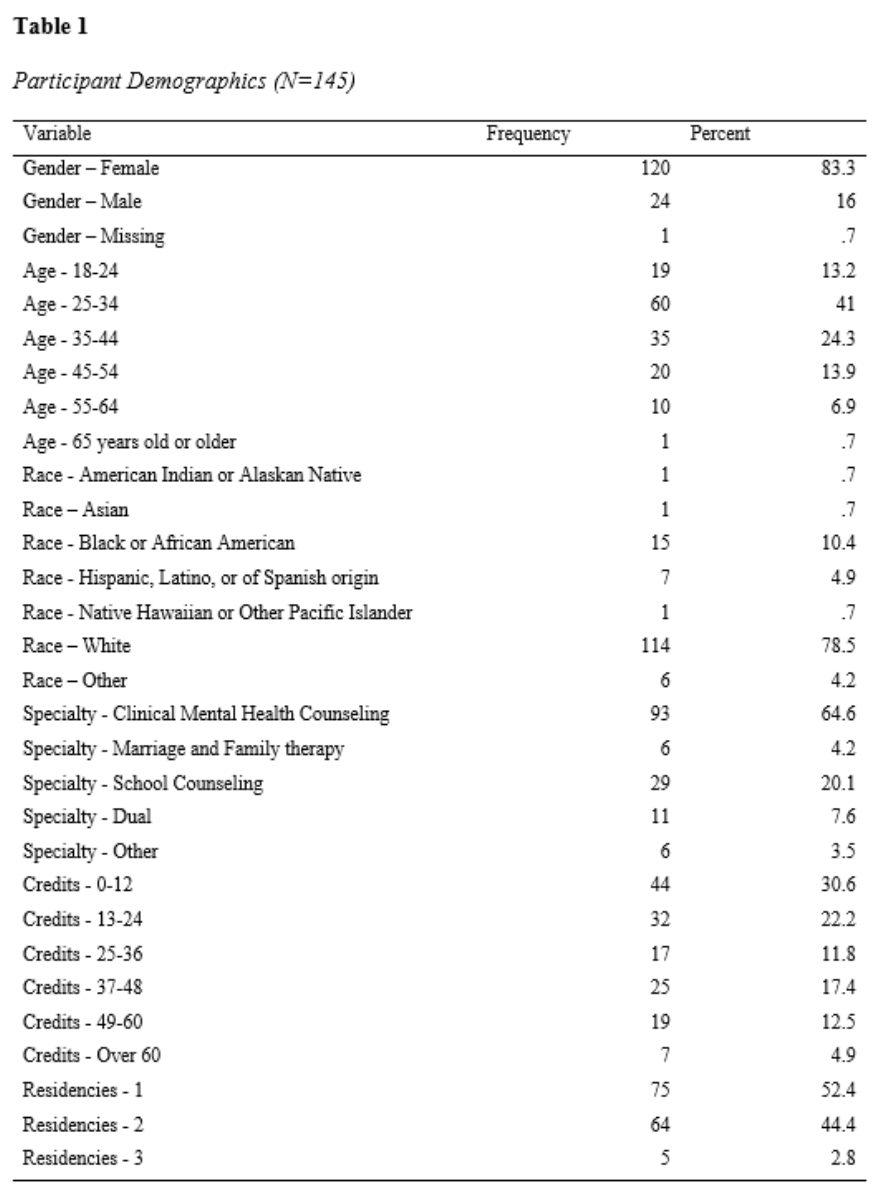

this assessment reported an internal consistency reliability with a Cronbach's alpha of .91 and a testretest reliability of $r=.85$; $p$ value not reported (Melchert et al., 1996). Mullen and colleagues (2015) found the reliability of the CSES acceptable, with a Cronbach's alpha of .96. Another researcher (Constantine, 2001), using counseling CITs, found that the CSES had an acceptable internal consistency, with a Cronbach's alpha of .77. In a more recent study with doctoral psychology students as participants, Pasquariello (2013) found that Cronbach's alpha ranged from .85-.93. The Cronbach's alpha calculated for this study was .92 . These scores suggested an acceptable level of internal consistency.

\section{Corrective Feedback Instrument-Revised} (CFI-R). The CFI-R is a revised instrument developed by Hulse-Killacky et al. (2006) to encourage discussion about giving and receiving corrective feedback in counseling training groups. The original instrument had 55 self-report items, revised to 30 in the CFI-R. All items had factor coefficients greater than or equal to .60 for internal consistency. The 
CFI-R consists of the following six factors: leader, feelings, evaluative, childhood memories, written, and clarifying. The items are measured in a 6-point Likert scale and scores range from 30-180. High scores on this instrument generally indicate high discomfort with corrective feedback.

Initial CFI-R testing included a sample of 277 CITs. Internal consistency was calculated for each factor. Cronbach's alpha were stated as follows: leader scale: .92; evaluative scale .89; feelings scale .91; childhood memories scale .91; written scale .85; clarifying scale .87. Overall Cronbach's alpha for the CFI-R was .92, indicating a high level of internal consistency. A statistical correlation was calculated between the CFI and the CFI-R. Results showed a high correlation of .962 contributing to the construct validity of the instrument (Hulse-Killacky et al., 2006). Cronbach's alpha based on the current study's data were as follows: leader scale: .50; evaluative scale: .92; feelings scale: .84; childhood memories scale: .90; written scale: .73; clarifying scale: .88. The leader scale had a noticeably lower internal consistency in this sample of students, perhaps due to the different learning modality than the original sample on which this instrument was normed. However, the overall Cronbach's alpha for the CFI-R differed only slightly in this study (.91), indicating an overall high internal consistency.

\section{Perceptions of Feedback Instrument (PFI).} The first author designed the PFI to measure perceptions of feedback. While the CFI-R measures attitudes toward corrective feedback in general, no reliable instrument measured perceptions of specific feedback. The PFI was based on a study conducted by Sohn (2009) on perceptions of feedback and mediating factors in perception, along with critical incident questionnaires on perceptions and specific recollections of experiences (Brookfield, 1996; Glowacki-Dudka \& Barnett, 2007). Questions on the PFI were developed for two subscale constructs, perceptions of positive feedback and perceptions of corrective feedback. Aspects of both positive and corrective feedback included the amount of feedback received, how positive or critical the feedback is perceived to be, and perceptions of helpfulness. Beattie et al. (2016) found that providing large amounts of feedback correlated positively with self- efficacy, and less amounts of feedback with less detail correlated negatively with self-efficacy. Sohn (2009) found that reactions to feedback depended on perceptions of positivity or negativity. Hills et al. (2016) found that CITs are interested in feedback that is helpful, and tend to perceive helpful feedback in positive ways, even when the feedback is corrective. Thus, construct validity for the design of these questions was supported through literature. The PFI instrument provides definitions of residency, corrective feedback, and positive feedback, then lists seven questions in Likert-scale format, with a continuum range of 1 to 10 as follows: "Not Much" to "A Lot"; "Not Balanced" to "Very Balanced"; "Not At All" to "Very"; "Not Helpful" to "Very Helpful."

Since the PFI had not been previously used, the authors used this study to pilot this instrument. Cronbach's alpha was conducted on the sample in this study for the two subscales, perceptions of positive feedback and perceptions of corrective feedback. The Cronbach's alpha for perceptions of positive feedback was .793, which indicated an acceptable level of internal consistency. Cronbach's alpha for perceptions of corrective feedback was .256, which indicated a low level of internal consistency. However, Briggs and Cheek (1986) recommended that internal consistency measures between different items on a scale range between .2 and .5 to show that they measure similar concepts but are different enough to measure diverse aspects of one construct. While the perceptions of feedback scale has a low level of internal consistency, the authors considered it adequate because it does range between .2 and .5 , as recommended by Briggs and Cheek (1986).

Given that this is the first time this instrument was used, the researchers will make adjustments for future studies to strengthen the instrument.

Demographic Questionnaire. The demographic questionnaire contained eight questions including gender, age, and cultural identity. Study-specific questions included counseling specialty, number of credit hours taken toward a counseling degree, program modality (online, face-to-face, hybrid), number of residency trainings attended, and year of last residency training. 


\section{Results}

Due to the exploratory nature of this pilot study, the researchers used a statistical multiple regression (Aron et al., 2008). We were interested in determining a parsimonious set of predictors that would significantly predict counseling students' self-efficacy during the residency portion of their online program (Tabachnick \& Fidell, 2013).

\section{Preliminary Analyses}

Prior to determining if data met the assumptions for multiple regression, data were assessed for univariate outliers by converting raw scores to $Z$-scores and using a cut-off value of $+/-3.28$ standard deviations (Tabachnick \& Fidell, 2013). Next, we used box and whisker plots to identify nonoutlying extreme scores. Finally, we examined the results of the Kolmogorov-Smirnov test for each variable to help us determine if the distributions met the assumption of normality $(p>.05)$. Descriptive statistics were also calculated, and skewness results were examined. The researchers examined normality of all nine variables. Six variables were not normally distributed based on their skewness and the results of the Kolmogorov-Smirnov test $(p>.05)$. Three variables had extreme, nonoutlying scores, according to the box and whiskers plots. These were transformed to the next highest or lowest nonextreme scores. Next, the researchers performed a square root transformation on all three variables to further improve normality. Transformations of extreme scores were performed for the following variables: CSES Total scores $(n=2)$; Positive Feedback $(n=$ 9); Clarify subscale of CFI-R $(n=3)$. No transformations were required for the other variables, as their skewness and kurtosis indicated a normal distribution.

Data were screened for multivariate outliers by creating a new variable, saving the Mahalanobis distance from a preliminary regression model. Critical Chi-square value was $(\mathrm{df}=9, p=.001)=$ 27.877. One case exceeded the critical Chi-square value and was excluded from further analyses. The multivariate assumptions concerning linearity and normality and homoscedasticity of the residuals was assessed by creating and examining a residuals scatterplot created from a preliminary regression model. The residuals scatterplot indicated all assumptions were met. The researchers assessed for multicollinearity by assessing the correlations between all predictor bivariate pairs. All bivariate pairs had correlations $<.7$, indicating that multicollinearity was not an issue. Additionally, all predictors had tolerance values > . 1 and VIF values < 10 .

\section{Statistical Analysis}

The researchers conducted a backward multiple regression to identify the most parsimonious combination of predictors (constructive feedback, positive feedback, leader, feelings, evaluation, childhood memories, written, and clarify) to predict counseling students' self-efficacy. Regression results indicated the final model of three predictors (constructive feedback, leader, and clarify) was statistically significant $\left[R^{2}=.088, R_{\text {adj }}^{2}=.067, F(3,136)=4.351\right.$, $p=.006]$ in predicting self-efficacy as measured by the CSES. This model accounted for $8.8 \%$ of variance in students' self-efficacy. A summary of the regression model is presented in Table 2. Additionally, bivariate and partial correlation coefficients for each predictor and criterion variable pairs are presented in Table 3.

To answer Research Question 1, (What is the relationship between perceptions of feedback (corrective and positive) and self-efficacy in a residency training setting?), it appears that only corrective feedback showed a significant positive correlation with self-efficacy $(r=.149, p=0.027)$. The relationship between positive feedback and self-efficacy was negative and not statistically significant ( $r$ $=-.085, p=.158)$. The results of the regression indicated that out of the two types of feedback - positive and corrective - only the latter was statistically significant in predicting counseling students' self-efficacy.

For Research Question 2, (Is there a correlation between attitudes toward corrective feedback and self-efficacy?), only two of the six subscales of the CFI-R were included in the final model predicting counseling students' self-efficacy. While both the leader scale and the clarify scale were included the final model, only the clarify scale $(r=-201, p=$ 0.026 ) showed a statistically significant (negative) relationship with self-efficacy. The leader scale $(r=$ $.155, p=0.093$ ) showed a non-statistically significant positive relationship with self-efficacy. 
However, it is important to note that this variable was significant as a bivariate correlation ( $r=$ $.155 ; p=.034)$.

\section{Discussion and Implications}

The main finding of this study was that CIT perceptions of corrective feedback was significantly correlated with self-efficacy. This finding aligns with existing literature that CITs seek and value corrective feedback (Bernard \& Goodyear, 2019; Fickling et al., 2017; Hills et al., 2016). While corrective feedback seemed to be more uncomfortable (Hulse-Killacky et al., 2006), receiving corrective feedback had a positive impact on CIT self-efficacy. CIT perceptions of positive feedback was positively correlated with self-efficacy; however, it was not statistically significant. These results are contrary to a previous experimental study in which positive feedback impacted self-efficacy (Daniels \& Larson, 2001). A possible explanation aligned with literature might be that CITs perceive positive feedback as inauthentic (Auxier et al., 2003; Ramani et al., 2017). This finding also supports the results of Fickling et al. (2017) that one of the least helpful events in supervision was not receiving any corrective feedback.

It appears in the final model that two factors of the CFI-R are significant predictors. Together with corrective feedback, the leader factor and the clarify factor significantly predict self-efficacy. The clarify factor showed a significant negative correlation with self-efficacy in the final model. The implications of these correlations may mean that participants who have difficulty with corrective feedback may also show lower self-efficacy, particularly if they have difficulty asking for clarification of feedback. This negative correlation between negative attitudes toward corrective feedback and self-efficacy may also mean that when CITs are open to corrective feedback, they also incorporate it into their practice, thus increasing their confidence in their skills. Having low levels of negative attitudes toward corrective feedback may help CIT preparation and skill mastery, leading to high levels of self-efficacy. The positive correlation with the leader factor may indicate that participants who feel comfortable with corrective feedback are also very supportive of the leader's attempts to set up an environment conducive to corrective feedback. CITs who are open to corrective feedback may have fewer associated negative emotions. This finding also ties in with Sohn's (2009) study where CIT attitude toward feedback together with the perception of the environment mediates the perception of negative or positive feedback. Thus, negative attitudes toward corrective feedback could influence perceptions of corrective

Table 2

Model Summary for Perceptions of Feedback and Self-Efficacy

\begin{tabular}{lllllllll}
\hline \multicolumn{1}{c}{ Step } & $R$ & $R^{2}$ & $R_{\text {adj }}^{2}$ & \multicolumn{1}{c}{$\Delta R^{2}$} & \multicolumn{1}{c}{$F_{\text {chg }}$} & \multicolumn{1}{c}{$p$} & $d f_{\text {J }}$ & \multicolumn{1}{c}{$d f_{2}$} \\
\hline 1 & $.324^{\mathrm{a}}$ & 0.105 & 0.050 & 0.105 & 1.920 & 0.062 & 8 & 131 \\
2 & $.323^{\mathrm{b}}$ & 0.104 & 0.057 & -0.001 & 0.085 & 0.038 & 7 & 132 \\
3 & $.322^{\mathrm{c}}$ & 0.104 & 0.063 & -0.001 & 0.106 & 0.022 & 6 & 133 \\
4 & $.314^{\mathrm{d}}$ & 0.099 & 0.065 & -0.005 & 0.726 & 0.015 & 5 & 134 \\
5 & $.306^{\mathrm{e}}$ & 0.094 & 0.067 & -0.005 & 0.759 & 0.01 & 4 & 135 \\
6 & $.296^{\mathrm{f}}$ & 0.088 & 0.067 & -0.006 & 0.910 & 0.006 & 3 & 136 \\
\hline
\end{tabular}

Table 3

Significant Coefficients for Final Model of Perceptions of Feedback and Self-Efficacy

\begin{tabular}{lrrrrrr}
\hline & $B$ & $\beta$ & \multicolumn{1}{c}{$t$} & $p$ & Bivariate $r$ & Partial $r$ \\
\hline Corrective & 2.892 & 0.185 & 0.185 & 0.027 & 0.149 & 0.188 \\
Leader & 0.432 & 0.143 & 0.143 & 0.093 & 0.155 & 0.144 \\
Clarify & -3.388 & -0.189 & -0.189 & 0.026 & -0.201 & -0.190 \\
\hline
\end{tabular}


feedback negatively, as well as perceptions of the environment in which the feedback is given. CITs with negative perceptions could have more difficulty integrating corrective feedback.

Feedback is essential in supervision and for developing self-efficacy (Bernard \& Goodyear, 2019; Daniels \& Larson, 2001). Both positive and corrective feedback are necessary in order to provide adequate supervisory information (ACES, 2011). However, many counselor educators do not feel prepared to adequately give corrective feedback and rely heavily on giving positive feedback (Hulse-Killacky et al., 2006). Providing corrective feedback appeared to be essential for CIT growth in self-efficacy and evidenced a trusting supervisory relationship (McKibben et al., 2019). An important implication of this study for counselor educators is that relying solely on positive feedback can be a disadvantage for CITs, supporting SCT and counselor developmental models (Bandura, 1977; Rønnestadt, \& Skovholt, 2003).

Incorporating corrective feedback may have a positive impact on CIT sense of agency because of increased understanding on how to improve performance. According to SCT, self-efficacy has four sources: performance accomplishments, vicarious experiences, verbal persuasion, and emotional arousal (Bandura et al., 1977). Of these four factors, the strongest in establishing self-efficacy is performance accomplishments. It is tempting to theorize that receiving positive feedback supports one's sense of performance accomplishment. However, verbal persuasion without an actual accomplishment that gives the subject a sense of mastery will not increase self-efficacy (Bandura et al., 1977). It is more likely that receiving helpful corrective feedback would give one a stronger sense of performance accomplishment after implementing the changes suggested by such feedback. It is the individual's perception of accomplishment that ultimately creates the sense of self-efficacy.

Counselor educators need to become familiar and comfortable with providing corrective feedback to CITs. This may begin with broaching the topic and addressing their apprehension about giving and receiving feedback (Hulse-Killacky et al., 2006; Swank \& McCarthy, 2013). Counselor educators are encouraged to normalize corrective feedback and facilitate an environment of low emotional arousal in CITs, to help them incorporate the corrective feedback easier and develop higher self-efficacy (Bandura, 1977). Counselor education programs may want to include mindfulness training for CIT emotion regulation skill development at the program level such as suggested by Bohecker et al. (2016).

Implications of this study may be the development of recommendations and best practices for ways in which supervisors and counselor educators provide corrective feedback. For example, the results of this study support The Counselor Feedback Training Model proposed by Swank and McCarthy (2013), in which CITs are taught how to give and receive feedback. Swank and McCarthy's model provided concrete activities and a framework for counselor educators to provide feedback norms in supervision and counselor education programs to integrate this training into the curriculum to increase CIT counseling self-efficacy.

Although Swank and McCarthy (2013) provide a model, missing from the literature are specific recommendations for communicating corrective feedback to CITs. It is time to conduct additional studies that provide an evidence base for new ways of giving CITs corrective feedback that are clear, specific, and helpful, thereby facilitating the incorporation of feedback and integration of changes in their practice. The results of this study showed that the impact of positive feedback was minimal, while corrective feedback has a significant and positive relationship with self-efficacy. What this means for counselor educators, supervisors, and counselor education programs is that providing positive feedback to CITs may not contribute much to the learning process, but alternatively, CITs appreciate meaningful, helpful, and well-thought-out corrective feedback (Hills et al., 2016).

\section{Limitations and Recommendations for Further Research}

Studies based on participant recollections result from events that occurred before data collection, therefore, it is possible that the perception changed or became less significant. The PFI instrument was designed to measure perceptions of feedback with limited information in the literature regarding what comprises the construct of feedback. Because as- 
pects of feedback have not been sufficiently developed in the literature, qualitative studies should be conducted on the lived experiences of CITs' perceptions of feedback in residency. This study was the pilot study for the PFI, and the low internal consistency of the corrective feedback scale is a limitation. Authors plan to revise the scale and conduct a follow-up study for the purposes of validating this instrument. Due to the exploratory nature of this pilot study and the researchers' use of statistical multiple regression, the researchers will attempt to validate the regression model in the full study by crossvalidating with data from the primary study's sample (Tabachnick \& Fidell, 2013).

The CFI-R measures negative attitudes toward corrective feedback, however, this instrument has been used mostly for discussion purposes, and few studies have established its validity and reliability for measuring attitudes toward corrective feedback (Hulse-Killacky et al., 2006). Understanding how CITs make meaning out of feedback will inform supervisory practices and can contribute to a better understanding of self-efficacy. A grounded theory study to develop a theory of how CITs make meaning out of corrective and positive feedback may inform counselor educators in their preparation of giving feedback (Bandura, 1977).

A completion rate is included in this study; however, the researchers do not know what the response rate is. Students from eight programs participated, however researchers do not know how many total students were in each program, or overall, in counseling programs. This can present as a limitation, as it is not known how large the general population was for CITs at the time of the study, or what percentage of that population responded to the study.

Quantitative studies could be conducted to evaluate feedback and the observable impact on CIT performance. Studies with objective measurements of counseling skills rather than self-reports would provide additional results about CIT skills and relationships to perceptions of feedback. The PFI should be used in other studies for further development, refinement, and psychometric evaluation. Understanding supervisory practices that ensure an environment in which emotional arousal is low, and where CITs can learn through vicarious experiences (Bandura, 1977), would promote better development of self-efficacy. The focus on feedback received in residencies for online CACREP-accredited programs limits generalizability to other supervisory settings.

\section{Conclusion}

This study provided empirical results on the correlations of CIT perceptions of positive and corrective feedback, and their relationships with self-efficacy in online counselor education residency settings. In contrast to previous study results, statistical significance was not found between CIT perceptions of positive feedback and self-efficacy. However, supporting more current research on feedback in supervision, CIT perceptions of corrective feedback correlated positively and significantly with self-efficacy. This finding may present a new challenge for counselor educators who are often very supportive and encouraging, and find providing corrective feedback difficult. To facilitate CIT development, the counseling profession may endorse a model of counselor feedback or develop specific best practices for supervisors and counselor educators to effectively provide corrective feedback.

\section{References}

Association for Counselor Education and Supervision Taskforce on Best Practices in Clinical Supervision (ACES). (2011). Best practices in clinical supervision. https://acesonline.net/wp-content/uploads/2018/11/ACES-Best-Practices-in-Clinical-Supervision2011.pdf

Anderson, E., Buchko, A. A., \& Buchko, K. J. (2016). Giving negative feedback to Millennials. Management Research Review, 39(6), 692-705. https://doi.org/10.1108/MRR-05-2015-0118

Aron, A., Aron, E. N., \& Coups, E. (2008). Statistics for the behavioral and social sciences: A brief course (4th ed.). Prentice Hall.

Auxier, C. R., Hughes, F., \& Kline, W. (2003). Identity development in counselors-in-training. Counselor Education and Supervision, 43, 25-45. https://doi.org/10.1002/j.1556-6978.2003.tb01827.x

Bandura, A. (1977). Self-efficacy: Toward a unifying theory of behavioral change. Psychology Review, 8, 191-215. https://doi.org/10.1037//0033-295x.84.2.191

Bandura, A. (1997) Self-efficacy: The exercise of control. Freeman Print.

Beattie, S., Woodman, T., Fakehy, M., \& Dempsey, C. (2016). The role of performance feedback on the self-efficacy-performance relationship. Sport, Exercise, and Performance Psychology, 5(1), 1-13. https://doi.org/10.1037/spy0000051

Bernard, J. M., \& Goodyear, R. K. (2019). Fundamentals of clinical supervision (6th ed.). Pearson.

Bohecker, L., Vereen, L. G., Wells, P. C., \& Wathen, C. C. (2016). A small group to help students tolerate ambiguity. Counselor Education and Supervision, 55(1), 16-30.

Borders, L. D., Glosoff, H. L., Welfare, L. E., Hays, D. G., DeKruyf, L., Fernando, D. M., \& Page, B. (2014). Best practices in clinical supervision: Evolution of a counseling specialty. The Clinical Supervisor, 33, 26-44. https://doi.org/10.1080/07325223.2014.905225 
Briggs, S. R., \& Cheek, J. M. (1986). The role of factor analysis in the development and evaluation of personality scales. Journal of Personality, 54(1), 106-148. https://doi.org/10.1111/j.14676494.1986.tb00391.x

Brookfield, S. (1996). Experiential pedagogy: Grounding teaching in students' learning Journal of Experiential Education. 19(2), 6268. https://doi.org/10.1177/105382599601900202

Burkard, A. W., Knox, S., Robyn, D. C., Phelps, D. L., \& Inman, A. G. (2014). Supervisors' experiences of providing difficult feedback in cross-ethnic/racial supervision. Counseling Psychologist, 42(3), 314-344. https://doi.org/10.1177/0011000012461157

Christensen, T., \& Kline, W. (2000). A qualitative investigation of the process of group supervision with group counselors. The Journal for Specialists in Group Work, 25(4), 376-393. https://doi.org/10.1080/01933920008411681

Claiborn, C. D., \& Goodyear, R. K. (2005). Feedback in psychotherapy. Journal of Clinical Psychology, 61(2), 209-217. https://doi.org/10.1002/jclp.20112

Council for Accreditation of Counseling and Related Educational Programs (2016). 2016 standards. http://www.cacrep.org/for-programs/2016-cacrep-standards/

Council for Accreditation of Counseling and Related Educational Programs. (2017). Accredited online programs. https://www.cacrep.org/directory/

Crockett, S., \& Hays, D. G. (2015). The influence of supervisor multicultural competence on the supervisory working alliance, supervisee counseling self-efficacy, and supervisee satisfaction with supervision: A mediation model. Counselor Education \& Supervision, 54, 258-273. https://doi.org/10.1002/ceas.12025

Daniels, J. A. (1997). The influence of performance feedback and causal attributions upon ratings of counseling self-efficacy. Dissertation Abstracts International: Section A. Humanities and Social Sciences, 58(6-A), 2068.

Daniels, J. A., \& Larson, L. M. (2001). The impact of performance feedback on counseling self-efficacy and counselor anxiety. Counselor Education \& Supervision, 41, 120-130. https://doi.org/10.1002/j.1556-6978.2001.tb01276.x

Efstation, J. F., Patton, M. J., \& Kardash, C. M. (1990). Measuring the working alliance in counselor supervision. Journal of Counseling Psychology, 37, 322-329. https://doi.org/10.1037//00220167.37.3.322

Fickling, M. J., Borders, L. D., Mobley, K. A., \& Wester, K. (2017). Most and least helpful events in three supervision modalities. Counselor Education and Supervision, 56(4), 289-304.

Friedlander, M. L., \& Snyder, J. (1983). Trainees' expectations for the supervisory process: Testing a developmental model. Counselor Education \& Supervision, 22, 342-348. https://doi.org/10.1002/j.1556-6978.1983.tb01771.x

Green, S. B., \& Salkind, N. J. (2014). Using SPSS for Windows and Macintosh: Analyzing and understanding data (7th ed.). Columbus.

Glowacki-Dudka, M., \& Barnett, N. (2007). Connecting critical reflection and group development in online adult education classrooms. International Journal of Teaching and Learning in Higher Education, 19(1), 43-52.

Hanson, M. G. (2006). Counselor self-efficacy: Supervision contributions, impact on performance, and mediation of the relationship between supervision and performance. Dissertation Abstracts: Sciences and Engineering, 67(8-B), 4708.

Hills, C., Levett-Jones, T., Warren-Forward, H., \& Lapkin, S. (2016). Generation Y students' views about the provision of feedback during clinical practice. Focus on Health Professional Education, 17(1), 32-47. https://doi.org/10.15453/2168-6408.1278

Hulse-Killacky, D., Orr, J. J., \& Paradise, L. V. (2006). The Corrective Feedback Instrument-Revised. The Journal for Specialists in
Group Work, 31(3), 263-281.

https://doi.org/10.1080/01933920600777758

Hook, J. N., Watkins, C. E., Jr., Davis, D. E., Owen, J., Van Tongeren, D. R., \& Ramos, M. J. (2016). Cultural humility in psychotherapy supervision. American Journal of Psychotherapy, 70(2), 149-166. https://doi.org/10.1037/0000037-005

Larson, L. M., \& Daniels, J. A. (1998). Review of the counseling self-efficacy literature. The Counseling Psychologist, 26(2), 179218. https://doi.org/10.1177/0011000098262001

McKibben, W. B., Borders, L. D., \& Wahesh, E. (2019). Factors influencing supervisee perceptions of critical feedback validity. Counselor Education and Supervision, 58(4), 242-256.

Meder, C. (2014). Counselor education delivery modalities: Do they affect student learning outcomes? Dissertation Abstracts $\mathrm{A}$ : $\mathrm{Hu}$ manities and Social Sciences, 74(12-A)(E).

Melchert, T. P., Hays, V. L., Wiljanen, L. M., \& Koloceck, A. K. (1996). Testing models of counselor development with a measure of counseling self-efficacy. Journal of Counseling \& Development, 74, 640-644. https://doi.org/10.1002/j.15566676.1996.tb02304.x

Meyer, D. D. (2012). Using drama therapy to explore religion and spirituality in counselor education. Counseling and Values, 57(2), 241-251.

Morran, D. K., Stockton, R., \& Bond, L. (1991). Delivery of positive and corrective feedback in counseling groups. Journal of Counseling Psychology, 38(4), 410-414.

Mullen, P. R., Uwamahoro, O., Blount, A. J., \& Lambie, G. W. (2015). Development of counseling students' self-efficacy during preparation and training. The Professional Counselor, 5(1), 175184. https://doi.org/10.15241/prm.5.1.175

Pasquariello, C. D. (2013). Enhancing self-efficacy in the utilization of physical activity counseling: An online constructivist approach with psychologists-in-training. Dissertation Abstracts International: Section B. Sciences and Engineering, 75(5-B)(E).

Papanagnou, D., Sicks, S., \& Hollander, J. E. (2015). Training the next generation of care providers. Healthcare Transformation, 1(1), 52-63. https://doi.org/10.1089/heat.2015.29001-psh

Quek, K., \& Storm, C. (2012). Chinese values in supervisory discourse: Implications for culturally sensitive practices. Contemporary Family Therapy: An International Journal, 34(1), 44-56. https://doi.org/10.1007/s10591-011-9172-4

Ramani, S., Post, S. E., Könings, K., Mann, K., Katz, J. T., \& van der Vleuten, C. (2017). "It's just not the culture": A qualitative study exploring residents' perceptions of the impact of institutional culture on feedback. Teaching and Learning in Medicine, 29(2), 153-161. https://doi.org/10.1080/10401334.2016.1244014

Rønnestadt, M. H., \& Skovholt, T. M. (2003). The journey of the counselor and therapist: Research findings and perspectives on professional development. Journal of Career Development, 30(1), 5-44. https://doi.org/10.1177/089484530303000102

Sanford, N. (1967). Where colleges fail: A study of the student as a person. Jossey- Bass.

Sohn, N. H. (2009). Effects of self-enhancement bias on perception of supervisory feedback in counseling. Psychological Reports, 105(3), 1269-1280. https://doi.org/10.2466/pr0.105.F.1269

Sterner, W. R. (2011). What is missing in counseling research? Reporting missing data. Journal of Counseling \& Development, 89(1), 56-62.

Stroud, D., Olguin, D., \& Marley, S. (2016). Relationship between counseling students' childhood memories and current negative self-evaluations when receiving corrective feedback. International Journal for the Advancement of Counselling, 38, 237-248.

Suhoyo, Y., Van Hell, E. A., Prihatiningsih, T. S., Kuks, J. B. M., \& Cohen-Schotanus, J. (2014). Exploring cultural differences in 
feedback processes and perceived instructiveness during clerkships: Replicating a Dutch study in Indonesia. Medical Teacher, 36, 223-229.

Swank, J. M., \& McCarthy, S. N. (2013). The Counselor Feedback Training Model: Teaching counseling students feedback skills. ADULTSPAN Journal, 12(2), 100-112.

Tabachnick, B. G., \& Fidell, L. S. (2013). Using multivariate statistics (6th ed). Pearson.
Tian, M., \& Lowe, J. (2013). The role of feedback in cross-cultural learning: A case study of Chinese taught post-graduate students in a UK university. Assessment \& Evaluation in Higher Education, 38(5), 580-598.

Watson, D. P. (1992). Counseling self-efficacy and counseling competence: A comparative study of clergy and counselors-in-training [Unpublished doctoral dissertation]. Purdue University, West Lafayette, Indiana. 